\title{
EFFECTIVENESS OF VARIOUS TEACHING METHODOLOGIES IN DEVELOPING CLINICAL REASONING SKILLS IN UNDERGRADUATE FEMALE MEDICAL STUDENTS
}

\author{
Saima Ali ${ }^{\boxplus}$, Brekhna Jamil', Liaqat Ali $^{3}$
}

\begin{abstract}
OBJECTIVE: To compare the effectiveness of "summarize, narrow, analyze, probing, management plan, select a topic" (SNAPPS) model, one-minute preceptor (OMP) and traditional clinical teaching in developing clinical reasoning skills of final year undergraduate female medical students in pediatrics clinical setting.

METHODS: This randomized control trial was conducted at Department of Pediatrics, Peshawar Medical College from February to July 2016. Students were randomly distributed in three groups i.e. SNAPPS, OMP and traditional teaching with 20 students in each group. All 60 students were exposed to pretest including 4 Key Feature Problems (KFPs). Students were then taught on pre-identified 4 topics with one topic/week by respective teaching methodology. Each topic was followed by post-test using 4 KFPs. The pre-test and post-test results were recorded and analyzed on SPSS-20. ANOVA was used as test for finding significance.
\end{abstract}

RESULTS: All 60 female students of final year completed the study and none dropped out. The mean marks of pretest of three groups were 12.50 \pm 0.15 with minimum number of $4 \pm I$ marks and maximum of $23 \pm I$. There was no significant difference in pre-test among the groups using ANOVA $(p=.984)$. However, significant difference $(p<0.00 \mathrm{I})$ was observed in post-test among groups after intervention. There was statistically significant difference $(p<0.001)$ in favor of SNAPPS as compared to traditional teaching methodology. There was no significant difference between OMP and traditional method.

CONCLUSION: SNAPPS is significantly more effective in improving clinical reasoning than OMP and traditional teaching method in female undergraduate medical students in pediatrics clinical setting.

KEY WORDS: Clinical reasoning (Non-MeSH); SNAPPS (Non-MeSH); Oneminute preceptor (Non-MeSH); Key feature problems (Non-MeSH); Education, Medical, Undergraduate (MeSH).

THIS ARTICLE MAY BE CITED AS: Ali S, Jamil B, Ali L. Effectiveness of various teaching methodologies in developing clinical reasoning skills in undergraduate female medical students. Khyber Med Univ J 20I8; I0(2):71-75.

\section{INTRODUCTION}

Solsong olving a problem or making correct diagnosis is called as clinical reasoning.' Clinical reasoning involve integration and applying different types of knowledge, collecting relevant data, critical thinking over an argument and reflection on process of making diagnosis.'
The time constraint is a major issue for clinical teachers in clinical setting as they are involved in multiple activities including patient care, solving administrative issue, research and teaching. ${ }^{2}$ So, there is always a need to develop time-efficient teaching methods in the clinical setting that can improve students' clinical reasoning skill
$1^{凶}$ Professor of Pediatrics, Peshawar Medical College, Peshawar, Pakistan

Email: drsaimaali 14@gmail.com Cell \# 0092-334-5455739

2 Assistant Professor, Khyber Medical University, Peshawar, Pakistan

3 Associate Professor, Institute of Kidney Disease, Peshawar, Pakistan

Date Submitted: July 15, 2017

Date Revised: March 21, 2018

Date Accepted: March 28, 2018

while also allowing the clinician to remain fully engaged in the priorities of patient care.

For learning clinical reasoning skill, there are several teaching methodologies e.g. "summarize, narrow, analyze, probing, management plan, select a topic" (SNAPPS), ${ }^{4}$ One-minute Preceptor (OMP), ${ }^{5}$ illness script writing, Aunt Minnie Model, thinking aloud exercises, 'highlighter exercises, ${ }^{6-8}$ reverse presentation, concept mapping ${ }^{9}$ etc. that can be used in busy clinical settings in Out Patient Department (OPD), inpatient setting and emergency. SNAPPS is an acronym used for learner-centered six steps model of case presentation while OMP is five steps technique including "get a commitment, probe for supporting evidence, reinforce what was done well, give guidance about errors and omissions and teach a general principle".

There is lot of discrepancy in literature regarding the effectiveness of one single method. Lap Ki used OMP in anatomy laboratory and found it an active learner-centered teaching approach which was also endorsed by Lockspeiser when he applied OMP in pediatrics and gynecology ${ }^{10}$ while Wolpaw considered SNAPPS as more learner-centered in ambulatory care. ${ }^{4}$

Eva Aagaard considered OMP as more effective in developing clinical reasoning skill of $92 \%$ students versus $76 \%$ in traditional method. " However, Wolpaw found SNAPPS as more effective than feedback and traditional method in expressing clinical reasoning skill. ${ }^{12}$ Although Farrell SE reported equal effectiveness of both the modalities in inpatient setting and in developing clinical reasoning skill of students but they also suggested additional studies. ${ }^{13}$ 
TABLE I: MEAN AND STANDARD DEVIATION OF POSTTEST OF INDIVIDUAL GROUP

\begin{tabular}{|c|c|c|c|c|c|c|c|c|}
\hline \multicolumn{9}{|c|}{ Posttest } \\
\hline \multirow{2}{*}{ Teaching Methodologies } & \multirow{2}{*}{$\mathbf{N}$} & \multirow{2}{*}{ Mean } & \multirow{2}{*}{$\begin{array}{c}\text { Std. } \\
\text { Deviation }\end{array}$} & \multirow{2}{*}{ Std. Error } & \multicolumn{2}{|c|}{$\begin{array}{l}95 \% \text { Confidence } \\
\text { Interval for Mean }\end{array}$} & \multirow{2}{*}{ Minimum } & \multirow{2}{*}{ Maximum } \\
\hline & & & & & $\begin{array}{l}\text { Lower } \\
\text { Bound }\end{array}$ & $\begin{array}{l}\text { Upper } \\
\text { Bound }\end{array}$ & & \\
\hline Traditional & 20 & 16.60 & 6.261 & 1.400 & 13.67 & 19.53 & 7 & 26 \\
\hline OMP & 20 & 20.05 & 7.294 & $1.63 \mid$ & 16.64 & 23.46 & 8 & 33 \\
\hline SNAPPS & 20 & 26.95 & 6.287 & 1.406 & 24.01 & 29.89 & 17 & 36 \\
\hline Total & 60 & 21.20 & 7.830 & 1.011 & 19.18 & 23.22 & 7 & 36 \\
\hline
\end{tabular}

OMP: "one-minute preceptor"; SNAPPS: "summarize, narrow, analyze, probing, management plan, select a topic"

The rationale of our research was based on the research question that which clinical teaching method among SNAPPS, OMP and traditional method is effective for improving clinical reasoning skill in undergraduate medical student? The objective of this study was to compare the effectiveness of SNAPPS, One-minute preceptor and traditional clinical teaching in developing clinical reasoning skills of final year undergraduate MBBS female students in pediatrics clinical setting.

\section{METHODS}

\section{Operational definitions:}

Traditional teaching methodology: Is defined as "already in practice, where teacher explains patient's condition to students, students and teacher examine the patient and then the teacher informs about diagnosis and management plan".

Clinical reasoning: We used LevettJohns definition of clinical reasoning as it was the recent one and more applicable in our situation. According to her, "When student is able to take relevant history, conduct physical examination, order required investigation, design effective management plan and counsel patient effectively" 7,14-17

Effectiveness: By effectiveness, we mean "Increase in score in posttest as compared to pretest."

This was a randomized control trial (Pretest-Posttest Control Group design) conducted in Department of Pediatrics, Peshawar Medical College, Peshawar, Pakistan from February to July 2016. A total of 60 female final year medical students were included in this study by stratified random sampling. The strata's developed as two groups, group I included those students who got $50-75 \%$ marks in last (third) professional examination while group II comprised of students who got $>75 \%$ marks. We excluded those students who had not attended the pediatrics clinical rotation in $4^{\text {th }}$ year. The purpose of this study was explained to the students and informed consent was taken in writing. After taking consent from the students, all participants were allocated to three groups with 20 students in each group by randomization with stratification. Group-A was taught by traditional clinical teaching. Group-B's teaching modality was OMP. Group-C was taught by SNAPPS. All the students were first subjected to pretest including four Key Feature Problems (KFPs). The KFPs were same for all three groups. On the first day of ward rotation, Students of SNAPP and OMP group were briefed according to their respective methodology and their questions about the method were

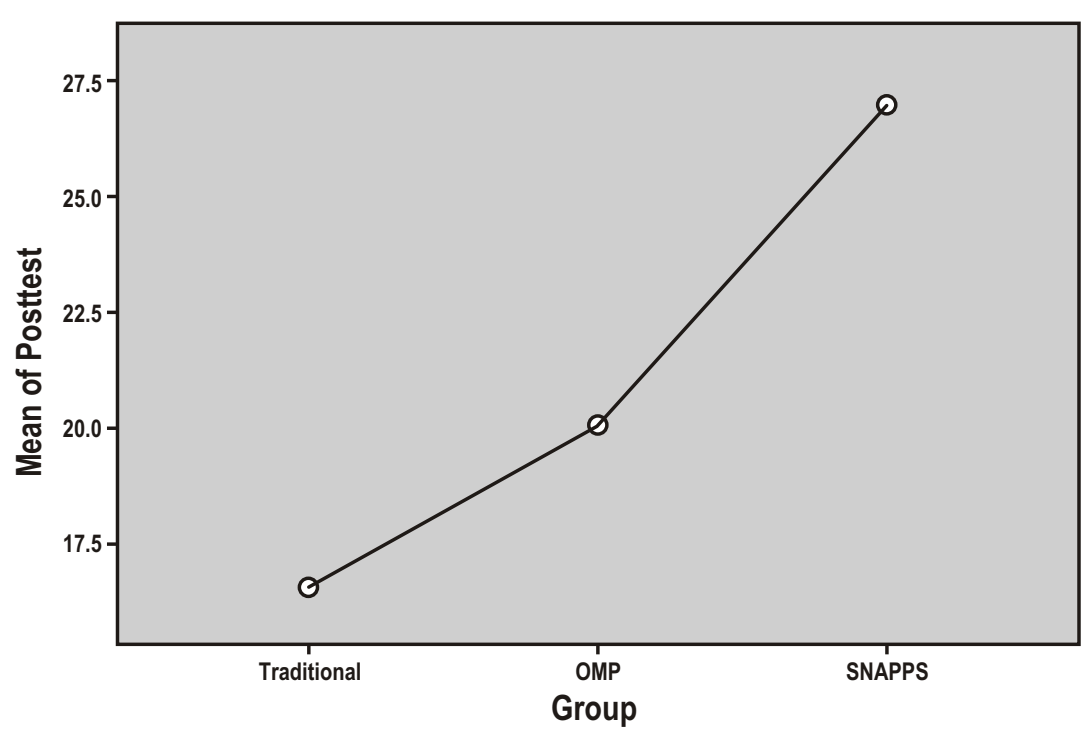

Figure I: Posttest means of three groups answered. All three groups were taught by the same teacher with respective methodology; one topic per week. The pre-identified topics were

I) pallor in children

2) hematuria in children

3) pyrexia of unknown origin in children

4) diarrhea in children.

At the end of teaching the identified topics, students of each group were exposed to post-test comprising of four different KFPs on same pre-identified topics, one KFPs/theme. The posttest was different from pretest but with same difficulty level. Each key feature problem in pretest and posttest was assigned 10 marks with the total of 40 marks.

After the posttest, it was ensured that all the three groups were taught by three methods (SNAAPS, OMP, and Traditional) in special classes.

Group 
TABLE II: MULTIPLE COMPARISONS OF POSTTEST BASED ON TUKEY'S HSD

\begin{tabular}{|l|l|c|c|c|c|c|}
\hline \multirow{2}{*}{$\begin{array}{l}\text { Teaching } \\
\text { Methodology }\end{array}$} & $\begin{array}{l}\text { Comparison } \\
\text { groups }\end{array}$ & \multirow{2}{*}{$\begin{array}{c}\text { Mean Difference } \\
(\mathbf{I}-\mathrm{J})\end{array}$} & Std. Error & Sig. & & \multicolumn{2}{|c|}{$\begin{array}{c}\text { 25\% Confidence Interval } \\
\text { Bound }\end{array}$} & $\begin{array}{c}\text { Upper } \\
\text { Bound }\end{array}$ \\
\hline \multirow{2}{*}{ Traditional } & OMP & -3.45 & 2.097 & .235 & -8.50 & 1.60 \\
\cline { 2 - 7 } & SNAPPS & $-10.35^{*}$ & 2.097 & .000 & -15.40 & -5.30 \\
\hline \multirow{2}{*}{ OMP } & Traditional & 3.45 & 2.097 & .235 & -1.60 & 8.50 \\
\cline { 2 - 7 } & SNAPPS & $-6.90^{*}$ & 2.097 & .005 & -11.95 & -1.85 \\
\hline \multirow{2}{*}{ SNAPPS } & Traditional & $10.35^{*}$ & 2.097 & .000 & 5.30 & 15.40 \\
\cline { 2 - 7 } & OMP & $6.90^{*}$ & 2.097 & .005 & 1.85 & 11.95 \\
\hline
\end{tabular}

OMP: “one-minute preceptor"; SNAPPS: "summarize, narrow, analyze, probing, management plan, select a topic"

*The mean difference is significant at the .05 level

We followed a structured seven-step process for KFPs proposed by AMEE Guide $87 .{ }^{18}$ Six KFPs on each topic with the total of 24 KFPs were formed. For content validation, $24 \mathrm{KFPs}$ were then sent to 10 experts including eight pediatricians and two medical educationists. Content validity ratio was calculated for each KFP through the formula derived by Lawshe's formula of content validity ratio.

We selected only those KFPs whose content validity ratio is 0.8 or more. Same eight pediatricians using 4- point Likert scale did face validity of these KFPs.

For assessing the reliability of questionnaire (KFPs), the questionnaire was tested on previous final year. Twenty five students of previous final year MBBS students who were on preparation leave for pre-professional (Mock) exam were randomly selected by lottery method. After finishing their Pediatric paper on the specified day, they were also called upon for the pilot study. As the exam was in college and current final year was supposed to be in clinical wards so there was no direct mixing of previous and current final year. In addition, till that time, current final year had no idea about enrollment in this study.

Twenty-one KFPs were tested for measuring the difficulty index. After item analysis, 16 out of 21 were selected. These KFPs were then distributed for pretest and posttests (SNAPPS, OMP, traditional teaching). Two KFPS were selected from medium difficulty and one each was selected from high and low difficulty index for each group.
The data was entered and analyzed by SPSS 20. One Way Analysis of Variance (ANOVA) was used as a unit of analysis. ANOVA was used to analyze the differences among group means and their associated procedures like "variation" among and between groups (OMP, SNAPPS, traditional). Comparisons of means square and standard deviation among groups for pretest and posttest were also analyzed.

\section{RESULTS}

All 60 female students of final year completed the study and none dropped out. The mean marks of pretest of three groups were $12.50 \pm 0.15$ with minimum number of $4 \pm I$ marks and maximum of $23 \pm \mathrm{I}$. The students in SNAPPS group performed better than OMP and traditional teaching in posttest. The mean marks of students in posttest with minimum and maximum marks obtained are shown in Table I and Figurel.

Our results showed that there is no significant difference in pretest among the groups using ANOVA with $(p=$ .984). However significant difference of $p=.000$ in posttest among groups after intervention.

There was statistically significant difference $(p=0.000)$ in favor of SNAPPS when traditional teaching methodology was compared with it. The SNAPPS has been proved more effective with significant difference $(P$ $=0.005$ ) when OMP was compared with SNAPPS methodology. We found no significant difference between OMP and traditional method as shown in table II. This mean difference was observed when $\alpha$ level was set at .05

\section{DISCUSSION}

Clinical reasoning is considered to be the core skill required for patient care but it was not taught explicitly in the past. ${ }^{19}$ The best method of teaching and assessing clinical reasoning is not yet unraveled and clarified. ${ }^{20}$

The strength of our study is that we chose KFPs for assessing clinical reasoning. KFPs are considered authentic, problem-based and with more interdisciplinary approach. ${ }^{21,22}$ In any real case, there is an essential element that is extremely important in decision making and KFPs is best for assessing this essential critical step in any clinical decision. ${ }^{23}$ The KFPs have longitudinal nature that enables the student to perform, like dealing with patient in real life. So, these are the few reasons that we chose KFPs which is considered a more valid written examination method of clinical decisionmaking skill. ${ }^{22}$ Moreover it is probably the first study in present setup that compared these three teaching modalities.

The present study revealed that students in SNAPPS group scored higher when compared with OMP and traditional teaching group with marks of 26.97 as compared to 20.05 and 16.60 respectively. Heinerichs $S$, et al. also reported that students showed marked improved in their posttest score with SNAPPS from baseline with $p$ value $<0.00$ I when compared with traditional group. $^{24}$

Wolpow TM, et al. ${ }^{4}$ in his randomized control trial-posttest only also found that students in SNAPPS training justified their differential diagnosis more 
than feedback training and traditional training groups i.e. ( 1.26 versus 0.22 and $0.23, P<.000)$. In another study by Wolpow concluded that students using SNAPPS technique justify patients management plan more often than the comparison groups $(84.84 \%$ versus $56.72 \%$ and $53.66 \%$ ) with $p$ value $.003 .^{12}$ The multiple comparisons of posttest in our study also showed statistically significant difference when we compare SNAPPS with OMP and traditional teaching with $p$ value of $0.000,0.005$ and 0.235 respectively.

Sawanyawisuth $\mathrm{K}$, et $\mathrm{al}^{25}$ observed improvement in case presentation of fifth year medical students with $p=$ 0.003 when compared SNAPPS users with traditional teaching method users.

Seki M, et al. ${ }^{26}$ found that residents in SNAPPS group used significantly more meaning units related to questions and uncertainties compared with those of OMP group i.e. $p<0.001$.

One study by Aagaard E,et al. " found no significant difference in the ability of students to correctly diagnose a problem' with $p$ value of 0.24 when she compared OMP with traditional teaching and we also found similar results in the present study i.e. $p=0.235$ when we did multiple comparisons of OMP with traditional teaching.

It is recommended that more research needs to be conducted in local setup before disseminating educational theories. Our second recommendation is that the areas like other disciplines and settings need to be explored in near future by doing further research. Further research is desired to estimate the content coverage in comparison to traditional inpatient settings and how do they impact the efficiency of teaching rounds.

\section{Limitation of study}

The limitation of our study is that we conducted this study only in female students because of the policy of Peshawar Medical College.

Second limitation of study was that it was conducted in department of pediatrics, so it cannot be generalized in other medical disciplines.

\section{CONCLUSION}

SNAPPS is significantly more effective in improving clinical reasoning than OMP and traditional teaching method in female undergraduate medical students in pediatrics clinical setting.

\section{ACKNOWLEDGMENT}

Authors would like to thank all the students of final year MBBS who participated in this study. We would also like to thank those pediatricians who contributed in content validation.

\section{REFERENCES}

I. Elstein AS. Thinking about diagnostic thinking: A 30-year perspective. Adv Health Sci Educ Theory Pract 2009 Sep;14 Suppl 1:7-18. DOI: |0.1007/s |0459-009-9|84-0.

2. Ramani S, Leinster S. AMEE Guide no. 34: Teaching in the clinical environment. Med Teach 2008;30(4):347-64. DOI: |0.1080/0|42|59080206|6|3.

3. Spencer J. $A B C$ of learning and teaching in medicine: Learning and teaching in the clinical environment. BMJ 2003;326(7389):59|-4.DOI: I0. I |36/bmj.326.7389.59 |

4. Wolpaw TM, Wolpaw DR, Papp KK. SNAPPS: A learner-centered model for outpatient education. Acad Med 2003;78(9):893-8.

5. Neher JO, Gordon KC, Meyer B, Stevens N. A Five-Step "Microskills" Model Of Clinical Teaching. J Am Board Fam Pract I 992;5(4):4 I 9-24.

6. Bowen JL. Educational Strategies to Promote Clinical Diagnostic Reasoning. N Engl J Med 2006;355:22। 7-25. DOI: 10.1056/NEJMra054782

7. Eva KW. What every teacher needs to know about clinical reasoning. Med Educ 2005;39(I):98- I06.DOI: I0.1 I I I/j. I365-2929.2004.01972.x

8. Edwards I, Jones M, Carr J, Braunack-Mayer A, Jensen GM. Clinical reasoning strategies in physical therapy. Phys Ther 2004;84(4):3 12-30; discussion 33 I-5.

9. Paucard-Dupont S, Marchand C.
Exploratory study of clinical reasoning in nursing students with concept mapping. Rech Soins Infirm 2014;(II7):85-II 2.

10. Lockspeiser TM, Kaul P. Applying the One Minute Preceptor Model to Pediatric and Adolescent Gynecology Education. J Pediatr Adolesc Gynecol 2015;28(2):74-7. DOI: I0.1016/j.jpag.2014.07.014

II. Aagaard E, Teherani A, Irby DM. Effectiveness of the one-minute preceptor model for diagnosing the patient and the learner: proof of concept. Acad Med 2004;79(I):42-9.

12. Wolpaw T, Papp KK, Bordage G. Using SNAPPS to facilitate the expression of clinical reasoning and uncertainties: a randomized comparison group trial. Acad Med 2009;84(4):5।7-24. DOI: 10.1097/ACM.0b0|3e31819a8cbf.

13. Farrell SE, Hopson LR, Wolff M, Hemphill RR, Santen SA. What's the Evidence: A Review of the Oneminute Preceptor Model of Clinical Teaching and Implications for Teaching in the Emergency Department. J Emerg Med $20 \mid 6 ; 5 ।(3): 278-3$. DOI: 10.1016/j.jemermed.2016.05.007.

14. Schmidt HG, Boshuizen HP. On the origin of intermediate effects in clinical case recall. Mem Cognit 1993;2I(3):338-5I.

15. Schmidt HG, Norman GR, Boshuizen HP. A cognitive perspective on medical expertise: theory and implication. Acad Med 1990;65(I0):6||-2I.

16. Linn A, Khaw C, Kildea H, Tonkin A. Clinical reasoning: A guide to improving teaching and practice. Aust Fam Physician 20 I 2;4 I (I-2): I 8-20.

17. Levett-Jones T, Hoffman K, Dempsey J, Jeong SY, Noble D, Norton CA, et al. The "five rights" of clinical reasoning: An educational model to enhance nursing students' ability to identify and manage clinically "at risk" patients. Nurse Educ Today 2010;30(6):5I5-20. DOI: I0.1016/j.nedt.2009.10.020

18. Artino AR Jr, La Rochelle JS, Dezee 
KJ, Gehlbach H. Developing questionnaires for educational research: AMEE Guide No. 87. Med Teach 20I4;36(6):463-74.DOI: |0.3109/0|42159X.20|4.8898|4

19. Gay S, Bartlett M, McKinley R. Teaching clinical reasoning to medical students. Clin Teach $20 \mid 3 ;$ I 0 (5):308-I 2. DOI: |0. I | I I/tct. 12043.

20. Rencic J. Twelve tips for teaching expertise in clinical reasoning. Med Teach 201 I;33(II):887-92.DOI: $10.3109 / 0142159 \times .2011 .558142$.

2I. Page G, Bordage G. The Medical Council of Canada's key features project: a more valid qritten examination of clinical decision- making skills. Acad Med 1995;70(2): 104-10.

22. Hrynchak P, Takahashi SG, Nayer M. Key-feature questions for assessment of clinical reasoning: $A$ literature review. Med Educ 20I4;48(9):870-83. DOI: I0.1 II I/medu. 12509 .

23. Farmer EA, Page G. A practical guide to assessing clinical decisionmaking skills using the key features a p p o a h. Med Ed u c 2005;39(I 2): I I 88-94.DOI: |0. I I I |/j.1365-2929.2005.02339.x

24. Heinerichs S, Vela LI, Drouin JM. A learner-centered technique and clinical reasoning, reflection, and case presentation attributes in athletic training students. J Athl Train 20I3;48(3):362-7I. DOI: 10.4085/1062-6050-48.2. 17.

25. Sawanyawisuth K, Schwartz A, Wolpaw T, Bordage G. Expressing clinical reasoning and uncertainties during a Thai internal medicine ambulatory care rotation: Does the SNAPPS technique generalize? Med Teach 20I5;37(4):379-84. DOI: $10.3109 / 0142159 \times .2014 .947942$.

26. Seki M, Otaki J, Breugelmans R, Komoda T, Nagata-Kobayashi S, Akaishi $Y$, et al. How do case presentation teaching methods affect learning outcomes?-SNAPPS and the One-Minute preceptor. BMC Med Educ 2016;16(1):12. DOI: |0.| |86/s|2909-0|6-053|-6.

\section{AUTHOR'S CONTRIBUTION}

Following authors have made substantial contributions to the manuscript as under:

SA: Acquisition of data, drafting the manuscript, final approval of the version to be published

BJ: Concept \& study design, drafting the manuscript, critical revision, final approval of the version to be published

LA: Analysis \& interpretation of data, drafting the manuscript, final approval of the version to be published

Authors agree to be accountable for all aspects of the work in ensuring that questions related to the accuracy or integrity of any part of the work are appropriately investigated and resolved.

This is an Open Access article distributed under the terms of the Creative Commons
Attribution-NonCommercial 2.0 Generic License.

KMUJ web address: www.kmuj.kmu.edu.pk

Email address: kmuj@kmu.edu.pk 